\title{
Metaphors of Development and the Development of Metaphors
}

Tania Zittoun and Alex Gillespie

\begin{abstract}
Development is a core theoretical issue for psychology. Yet, the root metaphors that guide theory and research on development have rarely been questioned, and the limitations and blind spots of these metaphors have not been made explicit. In this paper, we propose an exercise in theoretical imagination. We start by reviewing the metaphors commonly used in developmental psychology. We then develop four alternative metaphors that, despite being present in the general semiosphere, have not received much theoretical attention. In order to evaluate these metaphors, we introduce a case study of the development evident in a woman's diary. On this basis, we invite psychologists to examine new metaphors and thus expand the horizon of possible theorizing.
\end{abstract}

Keywords: metaphor; development; dialogism; growth; semiotic mediation

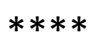

Development is a core theoretical issue for psychology. Despite much empirical work in developmental psychology, however, there has been little theoretical work conceptualizing development itself (Toomela, 2010; Toomela \& Valsiner, 2010; Valsiner, 2014). The root metaphors guiding research on development have rarely been questioned, and the limitations and blind spots of these metaphors have not been made explicit. Metaphors are enthralling; 
not only do they shape theoretical assumptions, guide empirical questions, and foster strong allegiances, but they also often operate unnoticed (Leary, 1994).

In this paper, we aim to make visible the available metaphors for conceptualizing human development. We start by reviewing the metaphors commonly used in developmental psychology. We then develop four alternative metaphors that, despite being present in the general semiosphere, have not received much theoretical attention. In order to evaluate these metaphors, we introduce a case study of the development evident in a woman's diary. On this basis, we invite psychologists to examine new metaphors and thus expand the horizon of possible theorizing.

\section{Theoretical Imagination}

The most common approach to making a theoretical argument is to review existing theories, reveal their limitations (theoretical, empirical, ethical), and then propose an alternative that overcomes the identified limitations. Such approaches combine deductions based on theory and inductions based on evidence to move toward new theoretical propositions. An alternative approach is an abductive one, wherein the focus is on theoretical leaps that reconceptualize and open up phenomena (Peirce, 1878; Tavory \& Timmermans, 2014). Abductive leaps can be facilitated by in-depth consideration of single case studies (Valsiner, 2019; Zittoun, 2017) or by engaging the theoretical imagination, such as the "geographical imagination" or "sociological imagination" (Harvey, 2006; Zittoun \& Gillespie, 2016). We pursue an abductive approach, emphasizing the ludic aspect of imagining new metaphors of development and juxtaposing them with the specifics of a single case study. Our aim is to generate metaphors of development and to theorize what they simultaneously hide and reveal. 


\section{Classical Root Metaphors}

Harkness and Super (2003) drew on Pepper's (1972) conceptualization of root metaphors of development, organizing them along two dimensions: analytic/synthetic and dispersive/integrative. This approach yielded four root metaphors: formism, mechanism, organicism, and contextualism (see Table 1).

Table 1

Four Metaphors for Development, Based on Super and Harkness (2003)

\begin{tabular}{lll}
\hline $\begin{array}{l}\text { Four metaphors of } \\
\text { development }\end{array}$ & $\begin{array}{c}\text { Dispersive: Interpreting the } \\
\text { parts one-by-one }\end{array}$ & $\begin{array}{c}\text { Integrative: } \\
\text { Relation between parts }\end{array}$ \\
\hline $\begin{array}{l}\text { Analytic: studying the parts } \\
\text { and their relations }\end{array}$ & $\begin{array}{l}\text { (1) Formism: } \\
\text { typologies, categories, } \\
\text { Aristotle }\end{array}$ & $\begin{array}{l}\text { (2) Mechanism: } \\
\text { causal relations between } \\
\text { parts }\end{array}$ \\
$\begin{array}{l}\text { Synthetic: studying the } \\
\text { parts in terms of the whole }\end{array}$ & $\begin{array}{l}\text { (3) Contextualism: } \\
\text { particular, history, multi- }\end{array}$ & $\begin{array}{l}\text { (4) Organicism: } \\
\text { systems, the whole, } \\
\end{array}$ \\
& perspective & Hegel/Marx \\
\hline
\end{tabular}

"Formism" focuses on making timeless typologies and attempting to identify levels or stages of development. This metaphor is common in personality psychology and disease classification. "Mechanism" operates according to the metaphor of a clockwork universe in which underlying variables exist in causal relationships with one another. Much empiricist developmental research occurs within this quadrant, for example, studies that associate parenting styles or educational interventions with cognitive outcomes. According to Super and Harkness (2003) neither formism nor mechanism is genuinely developmental; therefore, we will not consider these metaphors further.

"Organicism" is the root metaphor for most classical developmental models. Super and Harkness (2003) located Freud, Werner, Piaget, Maslow, and Kohlberg within this quadrant. Their approaches are synthetic, as they try to develop overarching models at the risk of 
obscuring some analytical distinctions. At the same time, their approaches are integrative, as they try to explain the relationships between parts. For example, according to Jean Piaget's genetic epistemology, development occurs when the system of schemes loses its equilibrium and is reorganized into a more integrative system to regain its equilibrium (Piaget, 1977). Comparably, Heinz Werner together with Bernard Kaplan (1963) proposed that development occurs through the progressive differentiation among processes and their hierarchical integration. In many ways, these models are compatible with dynamic system theories, converging on the idea that complex systems develop as their parts are reorganized into greater wholes following disruption (van Geert, 2009, 2019). The strength of these models, however, is also their weakness. In assuming that development is oriented toward a more integrated hierarchical system, they neglect processes that might undermine this progress, such as affective dynamics in Piaget (Duveen, 1997/2013; Perret-Clermont, 2008, 2015; Psaltis et al., 2015) and simplification in Werner (Gillespie \& Zittoun, 2013). While these models elucidate progress, their blind spot is disorganization and local regression.

"Contextualism," according to Super and Harkness (2003, p. 9), puts "emphasis on the local and individual construction of meaning." They distinguish between models emphasizing the interdependency of development with the historical context, such as in lifespan psychology, from theories that pay more attention to meaning and its situatedness, such as cultural psychology. It could be argued that the approaches located here share the synthetic movement of organicism and a tendency to identify one main developmental dynamic. In lifespan psychology, for example, the core dynamic is the SOC principle (selectionoptimization-compensation) that enables people to compensate for the loss of biological functioning with cultural heuristics (Baltes, 1997; Baltes et al., 1999). In the cultural-historical strand, the metaphor is often dialectical, in that, systems of activity may be challenged when 
they meet a crisis, but they can "expand" in more efficient systems through learning (Engeström, 2005). At a more microgenetic level, semiotic dynamics can lead the organism confronting the obstacle toward creative synthesis and reorganization through higher level mediation (Valsiner, 2001, 2013, 2015). Each of these approaches has its own blindspot, however. Activity approaches tend to overlook the psychic, whereas semiotic approaches tend to overlook the material context. Nevertheless, both approaches share a core idea of development as progress toward a more integrated, hierarchical, and robust system.

\section{Beyond Classical Metaphors}

Our interest lies in trajectories of human development that are enabled through microgenetic processes yet situated within changing social and historical environments. While this interest is naturally aligned with "contextualist" approaches, we also feel that the core metaphor of existing contextualist models does not make visible the full range of developmental processes. Simply put, the most interesting contextualist theories are based on the same metamodels as some of the organicist theories, involving the reorganization or transformation of a system to somehow transcend its previous state.

The metaphor of linear progress toward a system that is more inclusive, general, and effective, however, does not foreground the type of growth evident in most natural phenomena, such as the evolution of a species, the growth of an individual plant, or the development of a dialogue (Darwin, 1859/1964; Marková et al., 2007). These examples of natural development suggest that previous states are not completely left behind. For example, adults can empathize with the feelings and thoughts of the child, having once been a child themselves (Gillespie, 2012). One can rationally dismiss magical thinking, the belief that words might invoke events (Moscovici, 2014), and a belief in ghosts, but still understand, empathize, and to some extent feel these modes of thought. 
Importantly, this emphasis on linear progress can prevent us from integrating knowledge of other forms of development, which entail branching alternatives, regressions, or the coexistence of multiple parallel lines of development (Green, 2000, 2005; Vygotsky, 1929). Empirically, this linearity does not allow researchers to account for the fact that older people continue to develop as persons, despite becoming more physically frail (Hviid, 2020; Zittoun, 2020). Similarly, it does not account for life courses that have non-linear paths. Pragmatically, linear and normative models of development highlight the improvements in many people's quality of life brought about by scientific and technical progress, while failing to acknowledge the negative consequences of that progress (e.g., inequality, obesity, suicide). In light of these limitations, we need models that will enable us to move away from the idea that development is a linear movement progressing in one particular (privileged) direction, no matter how complex the movement is (e.g., Witherington, 2007). We propose that development is better understood spatially, as something with volume and multidimensionality. To this end, we explore metaphors that reveal the growth of the space itself, as a space of possible thought and action.

\section{Four Alternative Metaphors}

In discussing the core metaphor in developmental psychology, various metaphors for change have been imported from the natural sciences into the humanities and social sciences (e.g., catalysis (Cabell \& Valsiner, 2014)). Here, we move away from using physics and chemistry as models of thinking, instead seeking metaphors that enable us to think differently about our object of enquiry (Lakoff \& Johnson, 1980, 1999; Leary, 1994). First, we need metaphors that account for the diversity of human experience - an experience that takes place in the material world of bodies, facts, and objects - and can encompass a range of meanings and ideas. Second, to avoid linear outcomes, we turn away from the frequent focus 
of theories or models on outcomes, stages, and facts to focus on processes and dynamics (as for instance, Valsiner, 2001, 2019; van Geert, 2019). Third, we propose that, instead of focusing on what is thought or believed, we should focus instead on the space or breadth of possible thoughts and experiences, emphasizing multiplicity, agency, and open pathways. We therefore propose four alternative metaphors: development as a growing tree, a stream, a jazz improvisation, and a dialogue.

\section{Development as a Tree}

Nature offers rich metaphors to think about development as growth. This metaphor is evident in common sense: kindergarten (from German, 'children's garden') is a place where we nurture children's growth, and a nursery (from Latin, a person who nourishes children) is a place where trees are grown. The relationship between a person and their cultural environment has been described as a garden in cultural psychology (Cole, 1996). The metaphor of the "tree of life" has entered into life course psychology to designate the seasons of men (and women) (Shroots \& Birren, 2001). More specifically, trees grow by pulling living substance from both their leaves and roots, which are richly connected to the surrounding environment and plants. This growth adapts to its immediate environment; an obstacle - a fence or a stone - may change the tree's course, making each tree unique, yet recognizable. Each year's growth accumulates on what went before, rather than supplanting it, layering more experiences onto previous ones. Just like a cross-section of a tree trunk, a cross-section of human experience would show ring upon ring of accumulated experiences, with our formative experiences at the centre and our most recent experiences forming the bark. This metaphor invites us to question how each layer of experience informs the interpretation of the next, how each subsequent layer compensates for the former, how initial perturbations 
ripple through each subsequent layer of experience, and how all of these aspects together are the tree's 'development'.

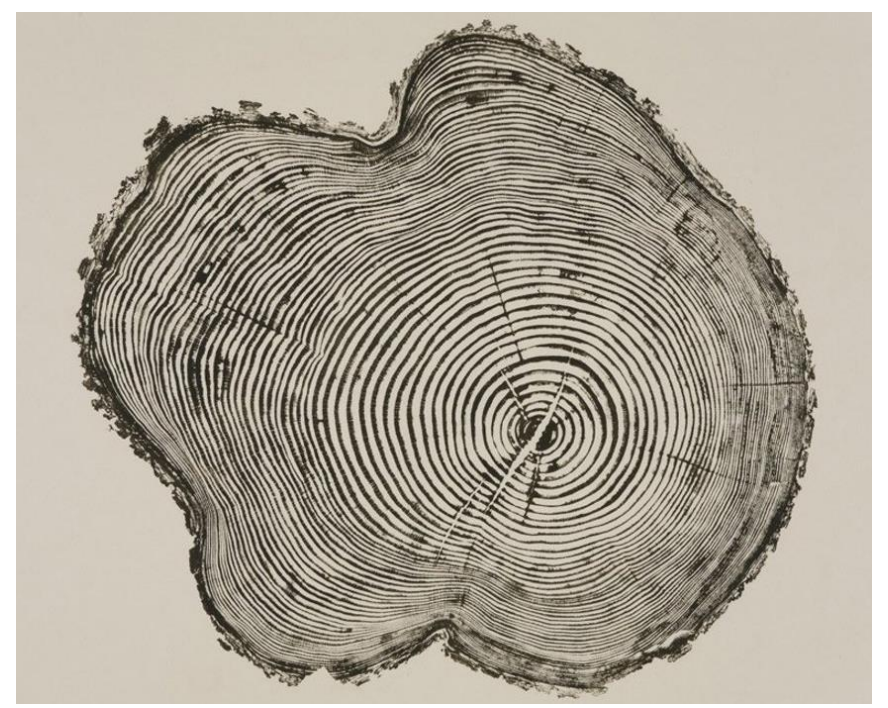

Figure 1. Cross-section of a tree

\section{Development as a Stream}

The metaphor of a stream or a flow has a long history in psychology. William James proposed to study the "stream of consciousness" (James, 1890, p. 239), an idea further pursued by Bergson (1938) and Freud (1940). We draw on the stream metaphor to conceptualize the life course, rather than to conceptualize the phenomenology of temporal consciousness. The life course flows as a river - channelled or running free, passing through wild waterfalls and tranquil pools. Its movement is non-linear; instead of 'progressing,' each river is a unique adaptation to its own natural environment. The movement can be slowed down or accelerated, the water erodes the river bed, rain increases the volume, and some water may evaporate. (Evaporation was a metaphor for thinking used by Vygotsky (Zavershneva \& van der Veer, 2018).) The stream metaphor admits multiple sub-streams and internal divisions; ice can cover the surface, while water flows underneath; stones and holes can create local whirlpools. In developmental psychology, roads rather than rivers have been used as a metaphor, and approaches inspired by dynamic systems theory use the idea of 
developmental pathways or tracks (Hundeide, 2005; Rutter, 1989). The TEM/TEA model shows bifurcation points in developmental courses represented as lines on a bi-dimensional plane (Sato, 2017; Sato et al., 2013). Although the stream metaphor shares the idea of branching pathways, we suggest a more dynamic and organic model. The river metaphor has volume and plurality; it is dependent on its environment, while having its own singular existence.

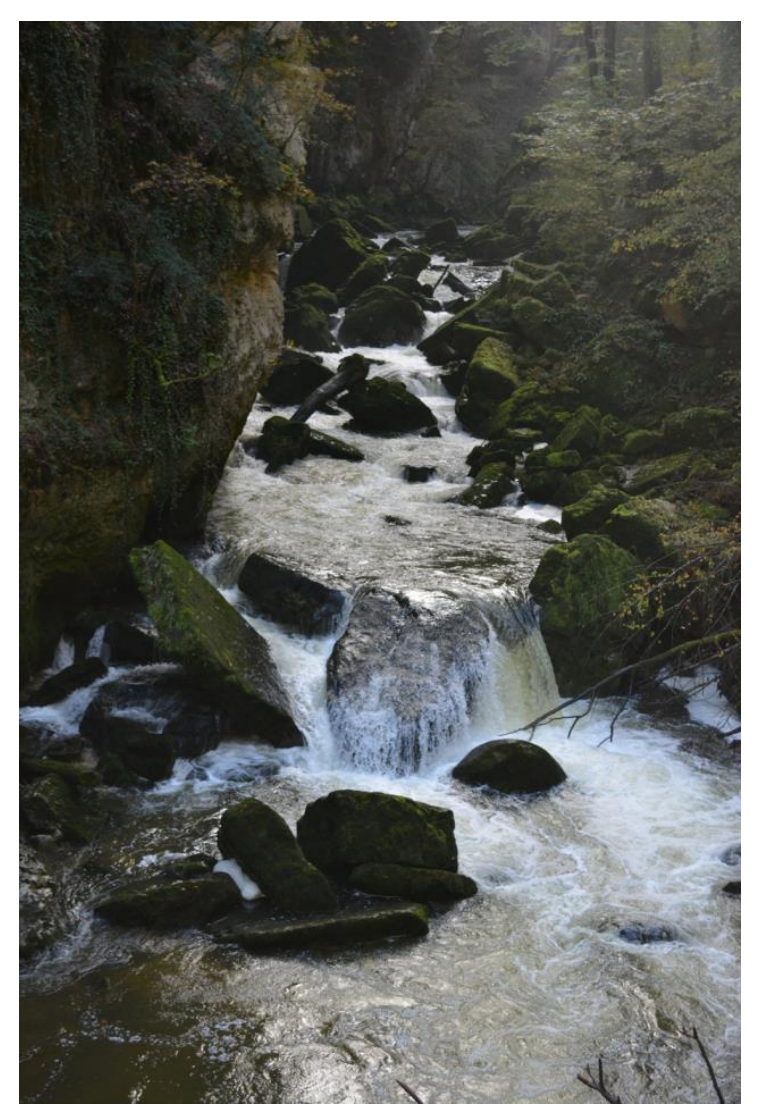

Figure 2. River

\section{Development as Improvised Jazz}

Music invites a focus on non-verbal patterns, rhythm, synchrony, and attunement in interaction. As such, it has offered creative metaphors for human development, especially among authors interested in infant interactions (Bradley, 2005; Malloch \& Trevarthen, 2008; Trevarthen, 2012). Improvised music in particular, such as in a jazz ensemble, presents a metaphor for development. The first notes create a theme or pattern, which good improvisers 
repeat, explore, and elaborate, diverging from it or introducing new propositions. In the process, a musical space opens up as duration, both with its own memory and as something always new. Locally, some themes (melodic, rhythmic, or harmonic fragments) may be recurrent enough to become reference points, as knots or more technically resources in this unfolding material. At some moments, all of the musicians may join together to create a sense of unison or harmonic response, while at others, they keep apart to independently explore the space of constantly expanding boundaries. Indeed, in improvised jazz, the development lies in the expansion of this space of possibility. Therefore, improvised music provides a metaphor of an expansive space unfolding in time, privileging embodied (non-verbal) meaning and interaction, with texture, tensions, harmonies, and closure.

\section{Development as a Dialogue}

Dialogical approaches have a long theoretical history (Linden \& Renshaw, 2004; Linell, 2009; Marková, 2003, 2016; Wegerif, 2013; Wells, 1999), based on a relational understanding of humans drawn from philosophy, the Talmud, and literary studies. The most influential variant was developed by Bakhtin (1975/1983) in his analysis of the novel. In the space of the novel, multiple voices coexist without being unified, and the tensions between those voices create the semantic space of the novel. For Bakhtin, utterances are located in various temporalities, both responding to the past and anticipating the future. These utterances are also charged with the harmonics and undertones of other situations, people, and voices. As many people and universes of meaning interact, the novel becomes a dialogical space of development, of potentially infinite possibility. We believe that it is this multiplicity and coexistence of possibilities and pathways that offers a rich metaphor for human development. In psychology, Marková (2000, p. 426) has drawn on Bakhtin's concept of "dialogical understanding" to describe what the social sciences do, namely, embodying and resonating 
with the diversity of voices, so as to build a rich understanding of a polyphonic and fractured social world. Broadening Bakhtin's insights, we can say that genuine dialogue is open-ended; no participant knows in advance how the dialogue will develop, and it makes little sense to delineate "progress" beforehand. Instead, what occurs is a creative emergence (Wegerif, 2005). However, each turn in the dialogue does not leave behind the prior turns; all turns, all meanings evoked become accumulated into the common ground of the participants, ready to contribute to the meaning of what is said or be pulled as resources into a new turn. In this way, turn-by-turn, a dialogue builds a shared space of possible talk and thought that grows organically, through accumulation, like an expanding balloon of shared understanding and possibilities.

\section{Illustrative Case Study}

We now introduce our case study material: a five-year diary from a young woman named June. The diary documents June's life during WWII in the UK. We consider her diary both an externalization of her flow of thinking and part of an attempt to guide her own development (Gillespie \& Zittoun, 2010; Zittoun \& Gillespie, Submitted chapter, 2012), Through close analyses, we have identified a range of inner dialogues and tensions that both characterize and contribute to that development, framing them in terms of two theoretical insights (Gillespie et al., 2008; Zittoun et al., 2008, 2012).

First, we distinguished in June's daily life a series of spheres of experiences, or patterns of conduct, feelings, aspects of the self, and ways of doing that are consistent enough across a certain activity or certain ideas to be, for that person, the "same" (Zittoun \& Gillespie, 2016): gardening with family, working at the garage, dancing with men. We also distinguished proximal from distal spheres of experiences, with proximal experiences taking place in the here-and-now (e.g., the actual experience of digging up potatoes on the farm) and distal 
experiences being achieved through imagination, by temporarily disengaging from the proximal experience (e.g., recalling one's childhood, becoming absorbed in a film, or imagining possible futures) (Gillespie \& Zittoun, 2013; Zittoun \& Gillespie, 2015a).

Second, our analysis revealed the importance of people's movements in the physical and geographical environment, which do not necessarily correspond to the person's movements of thought. As shown by Schuetz $(1944,1945)$ and Lewin $(1936,1943 / 2000)$, the space of a person's thought encompasses whatever is relevant to them at a certain point in time and space (Zittoun \& Gillespie, 2015b). This implies that, at any moment, the flow of consciousness can move through a wide diversity of experiences, recalling what other people said or did, their own experiences, a variety of cultural experiences, elements of social representations, and so on (Zittoun \& Cabra, In press; Zittoun \& Gillespie, 2016). If a person has to make a decision, or speak or act upon this flow of consciousness, one or more specific aspect or sphere of experience becomes mobilized as a resource and is accommodated to the new situation. However, very often, a plurality of experiences does not resolve into a new synthesis. Instead, the plurality, the tensions, the harmony, or the dissent play a key role, and differences are maintained in a space of possible thought that a person must explore through looping movements.

Having introduced June's diary as our case study and the foci of our previous analyses, we now turn to evaluating the four metaphors of development in terms of the concrete particulars of June's diary.

The tree metaphor elegantly reveals June's development through a series of adaptations to new circumstances (e.g., the war, being called to contribute to the war effort, meeting boys). It also reveals June's layering of experience: how her experiences from before the war and in her family remain present as core experiences, and how, as she meets young 
men during the war, those core experiences shape her responses to the new experiences. The tree metaphor also highlights the difference between an outer crust, which allows her to be efficient in the difficult conditions of her daily life, and the deeper layers of her experience, which make her feel vulnerable. Finally, this metaphor suggests interdependencies. Just as the tree, via its roots and leaves, can transform its environment, June's actions change the social and material conditions of her living. While June's new experiences are in relation to her older and deeper experiences, her older experiences can also be transformed by her new experiences. For example, June initially takes for granted the assumptions about women and marriage that she grew up with; however, through her experiences in the wider world, she comes to reinterpret those assumptions as parochial and narrow.

The stream metaphor reveals the ebb and flow of June's concerns, relationships, and thoughts. More effectively than the tree metaphor, the stream metaphor shows how the layers of June's experience can change each other. Just as cold water can come to the surface and be warmed by the sun, June's older memories are revised in the light of new events. While the river can also transform its environment, the fluidity of the model can also become its weakness; if everything flows, there is no stability, memory, or enduring patterns of experience that determine the person from within. Another limitation that is shared with the tree metaphor is that the river is relatively solitary, and both metaphors encourage us to focus on June alone. However, June's diary is populated with the voices of others (her mother, sister, employers, customers, boyfriends). Neither the river nor the tree metaphor foregrounds conceptualization of the other within the self (Gillespie et al., 2008). Finally, although both metaphors suggest vitality and endless variation in developmental routes, they can lead to assumptions about unidirectional progress (e.g., the river has a teleological purpose to reach the sea) - which we want to avoid. 
The jazz improvisation metaphor highlights the creative emergence of newness through interactions with people, resources, and places. For example, June, to her own surprise, enjoys working on the farms and dating boys. Even more than the river, the jazz improvisation metaphor emphasizes the plurality, spatiality, multivoicedness, tension, and harmony of human experience. During the piece, some emergent patterns remain in the soundscape to be returned to later on, taking a new harmonic turn, just as when June examines her life each New Year, comparing her present situation with her past, and having ruminations that might seem novel to her but which echo her concerns from previous years. The limitation of the jazz metaphor is that it is ephemeral, even more so than the river because of its relative permanence in the landscape. After the music has ended, what is left? Where is early childhood and where is old age? And where is the continuity between?

Finally, the dialogue metaphor reveals the internalization of multiple voices, which creates a shifting space of thought. Diaries are multivoiced phenomena (Aveling et al., 2015). June's diary is populated with the voices of other people, as well as films and radio broadcasts. June writes extensively about her mother, sister, employers, and boyfriends - their voices often in tension, instigating shifts of perspective and facilitating new evaluations of ongoing predicaments. The dialogue metaphor captures the multivoicedness that is opaque in the metaphors of the stream and the tree. However, like the jazz improvisation metaphor, development as a dialogue is ephemeral. Taken to the extreme, the individual is nothing but a fleeting soundscape of multivoiced dialogue, where the boundaries between self and other, and even start and end, can be difficult to discern.

\section{Discussion}

Metaphors are semiotic mediations that we can use as resources to make visible patterns and processes and guide our theoretical imagination. Earlier attempts to categorise 
root metaphors obscured differences and resemblances (Super \& Harkness, 2003), such as the core idea of progress. Our exploration of four metaphors, illustrated through one case study, similarly shows that revealing one aspect of development seems to come at the cost of concealing other aspects. Such enquiries indicate that it is difficult to capture the complexity of human sociocultural development - what changes and what remains the same (Hviid, 2012), what is generalized and what remains heterogeneous, what is due to the person and what comes from the world - in just one metaphor.

To summarize our analysis, we could say that each metaphor, as semiotic guidance (Valsiner, 2019), invites us to ask specific questions. The tree metaphor invites us to examine the layering of experience in life: How are new experiences interpreted in light of prior experiences? How do new experiences grow onto older experiences? How do new and old experiences interact? The river metaphor raises the questions: What is channeling development, guiding it toward certain outcomes? How does the person interact with their environment to create their own path? What are the ruptures in the flow; are they engineered or accidental? How is concrete experience generalized into a more diffuse experience (as in evaporation)? The jazz improvisation metaphor suggests considering how the whole of experience emerges out of seemingly minor and sometimes serendipitous events, which get picked up and elaborated: Why do some experiences become elaborated? What is dissonant within a life course? To what extent do people develop new patterns and a unique developmental style? The metaphor of a dialogue leads to questions such as: How do the voices of others and the social world become part of our psychological life? Where does the self end and the other begin? What are the internal dialogues that are both an outcome of and an input into development? 
Taken together, we see that the metaphors of the river, the tree, jazz improvisation and dialogue all reveal some interesting features of development. First, all these metaphors present us with the idea that development is highly dynamic and made up of diverse elements - waves, fibres, melodic lines, voices - that enable and shape each other. Furthermore, development is mutually dependent on an evolving environment. It is important to note that all of these metaphors propose alternatives to the dominant idea that development only occurs through integration to a higher form, even though they do so differently. Jazz and dialogue emphasize the possible tensions and frictions, yet at times harmonization and integration between elements, while stream and tree emphasize structural co-dependency and continuity. Second, these metaphors collectively reveal the idea that each occurrence of a river, tree, piece of music, or dialogue - has a specific shape or style. We must suspend our normative assumptions in order to apprehend the uniqueness of each instance. Trees, rivers, jazz improvisations and dialogues can develop under very different conditions and take many shapes, speeds, or forms. Appreciating the diversity invites us to push the boundaries of the type. Third, and most importantly, all four metaphors suggest that development is accompanied or enabled by the opening of a space of possibilities; in each metaphor, there is space, volume, multidimensionality, and multidirectionality to development. To account for these expansive movements of change, one has to examine the width, breadth, thickness, volume, and convoluted nature of elements and their relationships - not simply as a basic progression along one or two dimensions.

This exercise in theoretical imagination makes no claim to having solved the problem of theorizing human development in all its microgenetic, ontogenetic, and sociogenetic complexity. However, it suggests that playing with metaphors that offer alternatives to our well established metamodels may remind us of some aspect of the phenomenon we may have 
overlooked. Our core proposition is thus to invite researchers to expand the space of possibility around what development is.

\section{References}

Aveling, E.-L., Gillespie, A., \& Cornish, F. (2015). A qualitative method for analysing multivoicedness. Qualitative Research, 15(6), 670-687. https://doi.org/10.1177/1468794114557991

Bakhtin, M. M. (1983). The dialogic imagination: Four essays (M. Holquist, Ed.; C. Emerson \& M. Holquist, Trans.; Reprint edition). Austin: University of Texas Press. (Original work published 1975)

Baltes, P. B. (1997). On the incomplete architecture of human ontogeny. Selection, optimization and compensation of developmental psychology. American Psychologist, 52(4), 266-380. https://doi.org/10.1037/0003-066x.52.4.366

Baltes, P. B., Staudinger, U. M., \& Lindenberger, U. (1999). Lifespan psychology: Theory and application to intellectual functioning. Annual Review of Psychology, 50, 471-507. https://doi.org/10.1146/annurev.psych.50.1471

Bergson, H. (1938). La pensée et le mouvant. Paris, France: Presses Universitaires de France.

Bradley, B. S. (2005). Psychology and experience. Cambridge, UK: Cambridge University Press.

Cabell, K. R., \& Valsiner, J. (Eds.). (2014). The catalyzing mind: Beyond models of causality. London, UK: Springer.

Cole, M. (1996). Cultural psychology: A once and future discipline. Cambridge, MA: The Belknap Press of Harvard University Press.

Darwin, C. (1964). On the origin of species: A facsimile of the first edition. Cambridge, MA: Harvard University Press. (Original work published 1859) 
Duveen, G. (2013). Psychological development as social process. In S. Moscovici, S. Jovchelovitch, \& B. Wagoner (Eds.), Development as a social process. Contributions of Gerard Duveen (pp. 90-111). London, UK: Routledge. (Original work published 1997)

Engeström, Y. (2005). Developmental work research: Expanding activity theory in practice. Leipzig, Germany: Lehmanns Media.

Freud, S. (1940). An outline of psychoanalysis (New ed.). London, UK: Penguin Classics.

Gillespie, A. (2012). Position exchange: The social basis of agency. New Ideas in Psychology, 30(1), 32-46. https://doi.org/10.1016/j.newideapsych.2010.03.004

Gillespie, A., Cornish, F., Aveling, E.-L., \& Zittoun, T. (2008). Living with war: Community resources, self-dialogues and psychological adaptation to World War II. Journal of Community Psychology, 36(1), 35-52.

Gillespie, A., \& Zittoun, T. (2010). Studying the movement of thought. In A. Toomela \& J. Valsiner (Eds.), Methodological thinking in psychology: 60 years gone astray? (pp. 6988). Charlotte, NC: Information Age.

Gillespie, A., \& Zittoun, T. (2013). Meaning making in motion: Bodies and minds moving through institutional and semiotic structures. Culture \& Psychology, 19(4), 518-532. https://doi.org/10.1177/1354067X13500325

Green, A. (2000). La diachronie en psychanalyse. Paris, France: Editions de Minuit.

Green, A. (2005). Key ideas for a contemporary psychoanalysis misrecognition and recognition of the unconscious (1st ed.). London, UK: Routledge.

Harvey, D. (2006). The sociological and geographical imaginations. International Journal of Politics, Culture, and Society, 18(3-4), 211-255. https://doi.org/10.1007/s10767-0069009-6 
Hundeide, K. (2005). Socio-cultural tracks of development, opportunity situations and access skills. Culture \& Psychology, 11(2), 241-261. https://doi.org/10.1177/1354067X05052353

Hviid, P. (2012). 'Remaining the same' and children's experience of development. In M. Hedegaard, K. Aronsson, C. Hojholt, \& O. Ulvik (Eds.), Children, childhood, and everyday life: Children's perspectives (pp. 37-52). Charlotte, NC: Information Age.

Hviid, P. (2020). Aged experience: A cultural developmental investigation. Learning, Culture and Social Interaction. Advance online publication. https://doi.org/10.1016/j.Icsi.2020.100386

James, W. (1890). The principles of psychology: Vol. I. Mineola, NY: Dover.

Lakoff, G., \& Johnson, M. (1980). Metaphors we live by. Chicago, IL: University of Chicago Press.

Lakoff, G., \& Johnson, M. (1999). Philosophy in the flesh: The embodied mind and Its challenge to Western thought. New York, NY: Basic Books.

Leary, D. E. (1994). Metaphors in the history of psychology. Cambridge, UK: Cambridge University Press.

Lewin, K. (1936). Principles of topological psychology (F. Heider \& G. M. Heider, Trans.). New York, NY: McGraw-Hill.

Lewin, K. (2000). Defining the 'field at a given time'. In Resolving social conflicts \& field theory in social science (pp. 200-211). Washington, DC: American Psychological Association. (Original work published 1943)

Linden, J., \& Renshaw, P. (Eds.). (2004). Dialogic learning: Shifting perspectives to learning, instruction, and teaching. Dordrecht, Germany: Springer. 
Linell, P. (2009). Rethinking language, mind and world dialogically. Interactional and contextual theories of sense making. Charlotte, NC: Information Age.

Malloch, S., \& Trevarthen, C. (Eds.). (2008). Communicative musicality: Exploring the basis of human companionship. Oxford, UK: Oxford University Press.

Marková, I. (2000). Amédée or how to get rid of it: Social representations from a dialogical $\begin{array}{llll}\text { perspective. } \quad \text { Culture } \quad \text { \& } & \text { Psychology, }\end{array}$ https://doi.org/10.1177/1354067X0064002

Marková, I. (2003). Dialogicality and social representations: The dynamics of mind. Cambridge, UK: Cambridge University Press.

Marková, I. (2016). The dialogical mind: Common sense and ethics. Cambridge, UK: Cambridge University Press.

Marková, I., Linell, P., Grossen, M., \& Salazar Orvig, A. (2007). Dialogue in focus groups: Exploring socially shared knowledge. Sheffield, UK: Equinox.

Moscovici, S. (2014). The new magical thinking. Public Understanding of Science, 23(7), 759779. https://doi.org/10.1177/0963662514537584

Peirce, C. S. (1878). How to make our ideas clear. In Writings of Charles S. Peirce: A chronological edition (Vol. 3). Bloomington: Indiana University Press. Retrieved from http://www.marxists.org/reference/subject/philosophy/works/us/peirce.htm

Perret-Clermont, A.-N. (2008). Piaget, his elders and his peers. In A. N. Perret-Clermont \& J.M. Barrelet (Eds.), Jean Piaget and Neuchātel: The learner and the scholar (pp. 202231). London, UK: Routledge.

Perret-Clermont, A.-N. (2015). The architecture of social relationships and thinking spaces for growth. In C. Psaltis, A. Gillespie, \& A.-N. Perret-Clermont (Eds.), Social relations in 
human and societal development (pp. 51-70). London, UK: Palgrave Macmillan. https://doi.org/10.1057/9781137400994_4

Piaget, J. (1977). The development of thought: Equilibration of cognitive structures. New York, NY: Viking Press.

Psaltis, C., Gillespie, A., \& Perret-Clermont, A.-N. (2015). Introduction: The role of social relations in human and societal development. In C. Psaltis, A. Gillespie, \& A.-N. PerretClermont (Eds.), Social relations in human and societal development (pp. 1-15). London, UK: Palgrave Macmillan. https://doi.org/10.1057/9781137400994_1

Rutter, M. (1989). Pathways from childhood to adult life. Journal of Child Psychology and Psychiatry, 30(1), 23-51. https://doi.org/10.1111/j.1469-7610.1989.tb00768.x

Sato, T. (2017). Collected papers on trajectory equifinality approach. Tokyo, Japan: Chitose Press.

Sato, T., Yasuda, Y., Kanzaki, M., \& Valsiner, J. (2013). From describing to reconstructing life trajectories: How the TEA (Trajectory Equifinality Approach) explicates contextdependent human phenomena. In B. Wagoner, N. Chaudhary, \& P. Hviid (Eds.), Cultural psychology and its future: Complementarity in a new key (pp. 93-105). Charlotte, NC: Information Age.

Schuetz, A. (1944). The stranger: An essay in social psychology. American Journal of Sociology, 49(6), 499-507. https://doi.org/10.2307/2771547

Schuetz, A. (1945). On multiple realities. Philosophy and Phenomenological Research, 5(4), 533-576. https://doi.org/10.2307/2102818

Shroots, J. J. F., \& Birren, J. E. (2001). The studies of lives in progress: Approach to research on life stories. In G. D. Rowles \& N. E. Schoenberg (Eds.), Qualitative gerontology: A contemporary perspective (2nd ed., pp. 51-65). London, UK: Springer. 
Super, C. M., \& Harkness, S. (2003). The metaphors of development. Human Development, 46(1), 3-23. https://doi.org/10.1159/000067782

Tavory, I., \& Timmermans, S. (2014). Abductive analysis: Theorizing qualitative research. Chicago, IL: University of Chicago Press.

Toomela, A. (2010). Modern mainstream psychology is the best? Noncumulative, historically blind, fragmented, atheoretical. In A. Toomela \& J. Valsiner (Eds.), Methodological thinking in psychology: 60 years gone astray? (pp. 1-26). Charlotte, NC: Information Age.

Toomela, A., \& Valsiner, J. (Eds.). (2010). Methodological thinking in psychology: 60 years gone astray? Charlotte, NC: Information Age.

Trevarthen, C. (2012). Communicative musicality: The human impulse to create and share music. In D. J. Hargreaves, D. Miell, \& R. A. R. MacDonald (Eds.), Musical imaginations: Multidisciplinary perspectives on creativity, performance, and perception (pp. 259284). Oxford, UK: Oxford University Press.

Valsiner, J. (2001). Process structure of semiotic mediation in human development. Human Development, 44, 84-97. https://doi.org/10.1159/000057048

Valsiner, J. (2013). Creating sign hierarchies: Social representation in its dynamic context. Papers on Social Representations, 22, 16.1-16.32.

Valsiner, J. (2014). What cultural psychologies need: Generalizing theories! Culture \& Psychology, 20(2), 147-159. https://doi.org/10.1177/1354067X13515941

Valsiner, J. (2015). The place for synthesis: Vygotsky's analysis of affective generalization. History of the Human Sciences, 28(2), 93-102. https://doi.org/10.1177/0952695114559530

Valsiner, J. (2019). Ornamented lives. Charlotte, NC: Information Age. 
van Geert, P. (2009). Nonlinear complex dynamical systems in developmental psychology. In S. J. Guastello, M. Koopmans, \& D. Pincus (Eds.), Chaos and complexity in psychology. The theory of nonlinear dynamical systems (pp. 242-271). Cambridge, UK: Cambridge University Press.

van Geert, P. L. C. (2019). Dynamic systems, process and development. Human Development, 63(3-4), 153-179. https://doi.org/10.1159/000503825

Vygotsky, L. S. (1929). The fundamental problems of defectology. In A. Blunden (Trans.), Collected Works of L. S. Vygotsky (Vol. 2). New York, NY: Plenum Press. Retrieved from http://www.marxists.org/archive/vygotsky/works/1929/defectology/index.htm

Wegerif, R. (2005). Reason and creativity in classroom dialogues. Language and Education, 19(3), 223-237. https://doi.org/10.1080/0950078050866876

Wegerif, R. (2013). Dialogic: Education for the Internet age. London, UK: Routledge.

Wells, C. G. (1999). Dialogic inquiry. Cambridge, UK: Cambridge University Press.

Werner, H., \& Kaplan, B. (1963). Symbol formation: An organismic-developmental approach to language and the expression of thought. Hoboken, NJ: John Wiley \& Sons.

Witherington, D. C. (2007). The dynamic systems approach as metatheory for developmental psychology. Human Development, 50(2-3), 127-153. https://doi.org/10.1159/000100943

Zavershneva, E., \& van der Veer, R. (2018). Vygotsky's notebooks: A selection. London, UK: Springer.

Zittoun, T. (2020). Old age. In V. P. Glăveanu (Ed.), The Palgrave encyclopedia of the possible (pp. 1-8). Cham, Switzerland: Palgrave Macmillan. https://doi.org/10.1007/978-3319-98390-5_69-1 
Zittoun, T., Aveling, E.-L., Gillespie, A., \& Cornish, F. (2012). People in transitions in worlds in transition: Ambivalence in the transition to womanhood during World War II. In A. C. Bastos, K. Uriko, \& J. Valsiner (Eds.), Cultural dynamics of women's lives (pp. 59-78). Charlotte, NC: Information Age.

Zittoun, T., \& Cabra, M. (in press). Daydreaming. In V. P. Glăveanu (Ed.), Encyclopedia of the possible. Cham, Switzerland: Palgrave Macmillan.

Zittoun, T., Cornish, F., Gillespie, A., \& Aveling, E.-L. (2008). Using social knowledge: A case study of a diarist's meaning making during World War II. In W. Wagner, T. Sugiman, \& K. Gergen (Eds.), Meaning in action: Constructions, narratives and representations (pp. 163-179). London, UK: Springer.

Zittoun, T., \& Gillespie, A. (submitted chapter). A sociocultural approach to identity through diary studies. In M. Bamberg, C. Demuth, \& M. Watzlawik (Eds.), Cambridge handbook of identity. Cambridge, UK: Cambride University Press.

Zittoun, T., \& Gillespie, A. (2012). Using diaries and self-writings as data in psychological research. In E. Abbey \& S. E. Surgan (Eds.), Emerging methods in psychology (pp. 1-26). Piscataway, NJ: Transaction.

Zittoun, T., \& Gillespie, A. (2015a). Integrating experiences: Body and mind moving between contexts. In B. Wagoner, N. Chaudhary, \& P. Hviid (Eds.), Integrating experiences: Body and mind moving between contexts (pp. 3-49). Charlotte, NC: Information Age.

Zittoun, T., \& Gillespie, A. (2015b). Transitions in the lifecourse: Learning from Alfred Schütz. In A. C. Joerchel \& G. Benetka (Eds.), Biographical ruptures and their repairs: Cultural transitions in development (pp. 147-157). Charlotte, NC: Information Age.

Zittoun, T., \& Gillespie, A. (2016). Imagination in human and cultural development. London, UK: Routledge. 
For : Theory \& Psychology, 30 years 